\title{
THE EFFECT OF WĀNANGA-BASED LEARNING IN SUPPORTING THE DEVELOPMENT OF TEACHER AGENCY IN COMPUTATIONAL THINKING
}

He Rourou, Volume 1, Issue 1, 5-16, 2021

JESSICA PETERSEN

\section{ABSTRACT}

As of 2020, all schools and kura in Aotearoa New Zealand were expected to teach digital technologies as part of the core curriculum. Our digital world is rapidly expanding and in order to be successful in this space, our rangatahi (youth) need to be capable of both using and creating digital tools. This project seeks to support secondary-school teachers of different subject-specialty areas to authentically integrate computational thinking concepts into their regular teaching practice. This was accomplished through a series of wānanga and exploration phases, with a focus on critically reflective practice and ako (reciprocal learning). Questionnaires and recording of kōrero (conversation) were used to understand changes in teacher confidence in the areas of understanding, lesson design, and ability to give feedback in relation to computational thinking principles. Results of this research have shown that using wānanga to support teachers to learn and apply computational thinking in their classrooms positively impacts their agency in developing high-quality lessons that are aligned with digital technologies curriculum. The findings from this project are intended to support other schools in Aotearoa New Zealand to develop their own frameworks of professional development in this area.

Keywords: Computational Thinking, Professional Learning and Development, Digital Technologies, Education, Wānanga

\section{INTRODUCTION}

Digital technologies concepts and skills are increasingly required in New Zealand education settings and in the workplace (Ministry of Education, 2018b). Revisions to the New Zealand curriculum have emphasised the importance of digital technologies in supporting our tamariki to become confident, connected, actively-involved and lifelong learners (Ministry of Education, 2007). These revisions require students in all schools in Aotearoa from year one to year ten to meet digital technologies progress outcomes throughout their studies (Ministry of Education, 2018a). These progress outcomes are in the areas of computational thinking, and designing and developing digital outcomes. Therefore all schools within Aotearoa will deliver this new curriculum to ensure all students have the opportunity to learn about digital technology concepts.

This project was an initiative developed to enhance secondary-school kaiako (teachers) confidence to create, develop, and deliver computational thinking-focused learning experiences. This was done through the teacher (in collaboration with a digital technologies specialist) creating subject specific lessons, as well as a number of hui (meetings): an initial introduction to the concepts 
surrounding computational thinking and ideas of implementation in different subject areas; the creation of three lessons aligned with computational thinking concepts over the course of the project; and three wānanga (educational meetings) in which teachers gathered to discuss their experiences and further iterate on their lessons. Through this, I hoped to answer the question of how wānanga can support teachers in subject areas other than digital technologies to build agency in developing lessons that are aligned with digital technologies curriculum.

The participating school is a state secondary school located in South Auckland, New Zealand. It is situated in a relatively low-income community, and has an ethnically diverse student population. At the time of the research project the school had no plans to provide professional development opportunities to teachers in regards to digital technologies curriculum changes. This school has a well-established, comprehensive senior digital technologies programme, but its junior digital technologies programme is optional. As the participating high school does not offer digital technologies as a compulsory subject at a junior level, the school is required to integrate digital technologies concepts into other subject areas in order to meet new expectations set by the Ministry of Education. This also has the added benefit of ensuring that computational thinking concepts are explored in authentic and familiar contexts to the students. For this to be successful, however, teachers need to be confident in their abilities to develop and deliver digital technologies content.

\section{LITERATURE REVIEW}

\section{Best Practice in Professional Learning Development}

Best practice in professional learning development suggests that iterative programmes that allow for theoretical applications into existing practice are more effective at impacting student outcomes than one-time, prescribed practice initiatives (Joyce \& Showers, 1980).

\section{Expert Led vs Exploration Driven}

Almost all of the studies that were reviewed took this format, and all included some kind of expert either delivering presentations, presenting demonstrations, or both. The Ministry of Education states that there is little evidence that supports the idea that these activities actually affect teacher practice enough to impact student outcomes (Timperley et al., 2007). Joyce and Showers (2002) discovered that professional learning that included a component of collaboration and peer coaching was almost three times more effective than training that only included explanations, demonstrations, and practice. Garet et al. (2001) say that active engagement in meaningful discussion, planning and practice is a core feature of effective professional learning and development. Yadav et al. (2017) agree with this, adding that the context of information is also incredibly important. Participants need to be involved in more than just listening to speakers and the emphasis should be on developing skills instead of absorbing knowledge (active learning and cooperative learning). This approach - used by many professional development courses and conferences - leave participants in a passive and ineffective state of learning.

\section{Collaboration and a Māori Lens}

In Aotearoa (New Zealand), we have the benefit of Māori kaupapa that can help guide our learning in responsive ways that are specific to our unique context. Two core concepts of te ao Māori (the Māori world) that can directly support active learning are wānanga and ako. Wānanga describes a dynamic learning environment reliant on the sharing of knowledge, experiences, feedback, and debate. Ako is the idea that all people have valuable knowledge to share and that 
learning takes place as kōrero (conversation) between equals, rather than expert-led instruction (Bishop et al., 2007). This concept is usually seen in New Zealand classrooms as teachers learning from their students. This kaupapa Māori (Māori concept) contrasts directly with the approach of most existing research in the area of teacher professional learning and development in the area of computational thinking, and is supported by the recommendations of best practice in New Zealand (Allan et al., 2010; Blum \& Cortina, 2007; Garet et al., 2007; Hickmott \& PrietoRodriguez, 2018; Imberman et al., 2014; Morreale et al., 2010; Yadav et al., 2014). Professional learning and development should follow these principles in order to provide an active learning environment that is most beneficial to the learning of our teachers.

\section{Providing Resources vs Transformation of Teaching Practice}

A large number of the existing studies highlight that professional learning development focuses on tools or provided resources, rather than the teaching practice that supports them (Allan et al., 2010; Blum \& Cortina, 2007; Hickmott \& Prieto-Rodriguez, 2018; Imberman et al., 2014; Morreale \& Joiner, 2011; Morreale et al., 2010; Yadav et al., 2014). While this in itself is not problematic, research says that the most effective change in teaching practice occurs when teachers utilise tools and techniques provided by professional learning opportunities to influence their individual teaching practice (Timperley et al,, 2007). For true change to occur, resources and tools provided during professional learning need to be adaptable to each teacher's context (Yadav et al., 2017). Joyce and Showers (2002) found that teachers who did not have the skills to utilise learning in their own curriculum areas often abandoned new practices after running out of activities provided or demonstrated to them. In order for practice changes to be sustained, professional learning needs to equip teachers with the skills to innovate with new practices. In addition to this, as Guskey and Yoon (2009) mention, the focus on tools and provided resources also has the inherent risk of creating an "echo chamber", where practice and tools that participants already believe to be effective are emphasised, rather than encouraging the use of methods that are proven to produce results. The individualisation of learning programmes is just as important to student success as it is to professional learning development for teacher practice, and in this project, a focus will be put on this to further encourage change in student outcomes.

\section{Single-Occurance Workshops vs a Learning Journey}

According to the New Zealand Ministry of Education, powerful professional learning experiences should allow for teachers to revisit, reflect, and grow in their knowledge and understanding over a period of time (Timperley et al., 2007). This does not mean that time in itself is impactful, but rather that time spent engaging with new ideas and understanding their implications for teacher practice were important for growth (Garet et al., 2001; Timperley et al., 2007). Joyce and Showers (2002) identify that training programmes that allow for follow-up training, and peer collaboration and support lead to more consistent implementation in regular classroom practice than singleoccurrence, training-focused workshops. Guskey and Yoon (2009) acknowledge this, but argue that one-time initiatives like workshops have been proven to result in positive improvements in student outcomes. However, the workshops they studied focused heavily on active learning activities and opportunities for practice adaptation, which have been described as key to effective professional learning and development by the New Zealand Ministry of Education (Timperley et al., 2007). Additionally, in that research, only nine of the 1343 studies were deemed "credible" enough to be used to inform their opinions. Timperley et al. (2007) agree with the New Zealand Ministry of Education (2008) and stress the importance of learning taking place in everyday contexts in order to accurately and authentically experience the new knowledge. Despite this, 
many of the existing professional learning development studies in the area of computational thinking are one-off workshop efforts, and do not provide support over a period of time and follow a one-time model (Allan et al., 2010; Blum \& Cortina, 2007; Hickmott \& Prieto-Rodriguez, 2018; Imberman et al., 2014; Morreale \& Joiner, 2011; Morreale et al., 2010; Yadav et al., 2014).

Of the eight projects reviewed, only one aligned with an extended, iterative, and adaptive practicebased approach, as suggested by best practice research explained above.

\section{METHODOLOGY}

This project relied on gathering a range of qualitative and quantitative data from teachers participating in the project. The project was intended to be a series of workshops with time for exploration of content between them. Data was gathered to understand supporting teachers in learning areas other than digital technologies helps them to build their agency in developing highquality lessons that are aligned with digital technologies curriculum. This data came in the form of questionnaire responses and kōrero from wānanga.

\section{Recruitment of Teachers}

Participating teachers were invited openly from core subject areas, and as a result of this I recruited a diverse range of teachers from different cultures, values, and preferred learning-styles. This means that participants were able to draw from the experiences and world-views of a wide range of practitioners and through this, improve the accessibility of their lessons to meet the needs of all of their learners. This was a vital part of this project as it was focused on reducing inequality of access to quality computational thinking education, both within and outside the classroom. For the participants, the major outcomes for the project were aimed to be growth in their own understanding of computational thinking concepts and confidence in applying this knowledge to lessons in their own classrooms.

\section{Ethics}

Participating teachers were provided with an information sheet detailing the process and expectations of their involvement. They were also given an opportunity to ask any questions related to the kaupapa. Participating teachers then indicated their written consent to take part in the research with the opportunity to opt out of participation at any time, use of their images, and use of data produced by their participation. Ethics were approved by an IRB.

\section{Wānanga}

The project focused on wānanga principles in order to meet best professional learning practice identified earlier (Joyce \& Showers, 1980). Wānanga allowed teachers to explore the learning together through collaboration and ako over a number of sessions. Joyce and Showers (2002) suggest that the peer coaching and reflection linked to this process is almost three times more effective than learning that involves only explanation, demonstration, and practice. Wānanga also encouraged teachers to explore what computational thinking could look like in their own contexts, and develop ideas that could support learning specific to their own subject areas. As suggested by Timperley et al. (2007) learning that can directly be applied to teachers' existing practice is most effective when compared to learning that can not. Current in-school professional learning practice at the participating school relies on single-occurrence, one hour sessions, most often with only explanation and demonstration. This does not align with best professional 
development practice. Wānanga was intentionally utilised by this project to align closely with best professional development practice and culturally sustaining kaupapa.

\section{DATA COLLECTION}

\section{Questionnaire}

Questionnaires were used to monitor the progress of participants in the areas of how they are feeling in regards to their skills of developing digital technologies-aligned lesson plans as the project progressed. These questionnaires allowed participants to describe their confidence in lesson planning, confidence in giving feedback and feedforward, and understanding and awareness in relation to computational thinking. The questionnaire was given four times - once before the first hui, and three further times after each hui. This was to ensure that participants were given time to make connections with new learning, and to allow them to explore what new ideas mean in their own contexts. Each questionnaire contained the same questions, and asked participants to rate their confidence in each area of study on a scale of one to six.

Questionnaire was chosen as the appropriate method to formally gather this quantitative data because of its efficiency and consistency. Questions were focused on the specific data that was needed, which meant that this data was always reliably collected when it may not have been identified through discussion. Consistent data was essential in seeing the growth of participants in each area over time. Using the same set of questions throughout the data gathering process meant that there could be no discrepancies caused by differences in the wording of and understanding of questions. Reliability of data collection can sometimes be a concern with surveys, especially in regards to response rate. A high response rate was encouraged in this research through the use of allocated time to complete the survey during hui. The questionnaire was made intentionally very short to avoid burdening participants with a longer time commitment. There was only one incidence of non-response and this was a result of the participant being absent from the hui. Efficiency in questioning came at the cost of the richness of data gathered, especially as interviews could have provided more information. To limit the impact of this, kōrero during wānanga was also recorded to support the formal data gathered as well as provide additional insight into each teacher's experience.

Unfortunately due to the long periods between questionnaires, it was common for participants to forget their previous responses, and therefore accurately identify changes in understanding. This is another situation where observed kōrero was key to supporting any questionnaire responses given by participants.

\section{Kōrero}

It is important to recognise that while the questionnaire was the formal avenue of data collection, observation and kōrero during wānanga was key to the findings as well.

Kōrero during wānanga was recorded to better understand the process of each participant's learning. This was recorded as my own informal observations, and made available to participants on request for their own records. Observations included the descriptions and reflections on lessons delivered as part of the project, as well as any additional kōrero that was observed in relation to the project aims.

The recording of kōrero was a suitable method of data gathering because it allowed for rich qualitative data and genuine responses. The data gathered from conversations at the hui was 
rich in content and substantiated statements made by participants in the questionnaire. It gave better clarity on why they answered the questionnaire in each way, and the relatively unstructured flow of the hui meant that participants could freely offer perspectives and improve their own understanding through ako. A structured approach is often used for focus groups in order to ensure completeness and continuity between interviewees, but this was not a priority in this case as the data was supplementary to quantitative data gathered by the questionnaire. For this research, the main purpose of hui was both ako and reflecting on the journey that we were undertaking as a rōpū (group). The structure was left intentionally fluid to enable an organic flow of conversation and provide a safe space to encourage the discussion and debate of ideas. Additionally, this process was intended to enable a relaxed environment where all parties involved in the kōrero were treated as equals, as a more structured focus group setting may have established an impression of power imbalance between myself and the participants and affected the data that was gathered.

\section{Refinements to Wānanga}

Changes were made between wānanga to strengthen the data gathering process. The questionnaire was presented more clearly after the first wānanga, and participants were expected to complete it before they left the hui. This was as a result of late responses that could have impacted on results as participant's understanding of computational thinking concepts and their applications grew over time. Notes from the wānanga were shared with participants after each session were shared with participants in order to ensure their validity. This change was made after participants expressed interest in the notes that had been taken.

\section{FINDINGS}

Overall, the biggest change in all areas (awareness and understanding of computational thinking; confidence in designing lessons with computational thinking elements; confidence in giving feedback/feed-forward/clarification in regards to computational thinking concepts) came after the first hui where participants were introduced to the decomposition and algorithm design areas of computational thinking (Figure1, Figure 2, Figure 3). Beyond this, there was generally a gradual increase over time in confidence as further lessons were developed and delivered, as shown in Figures 1, 2, and 3. This aligns with Timperley et al. (2007) who highlight that practicetransforming professional learning development is most effective as a journey, or learning, experimenting and reflection, rather than a one-time experience. 
6

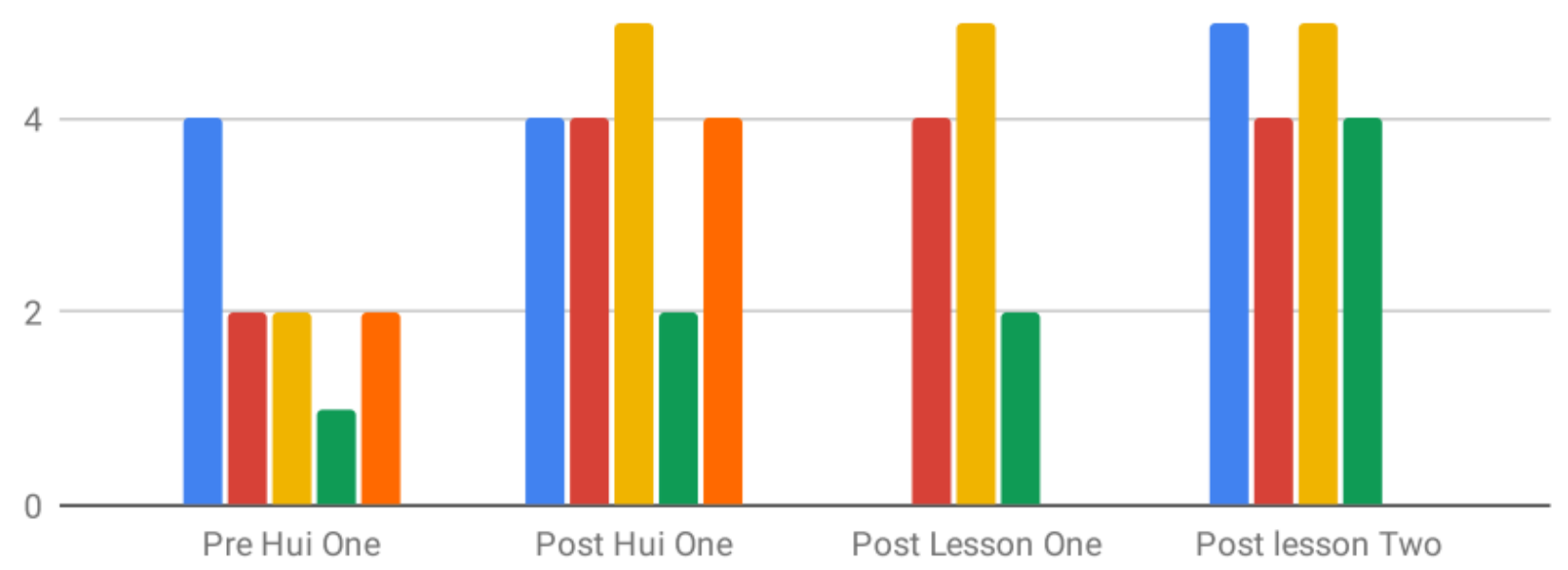

Figure 1. Awareness and Understanding of Computational Thinking as Reported by Participants Over the Duration of the Project
Participant A
Participant B
Participant C
Participant D
Participant E

6

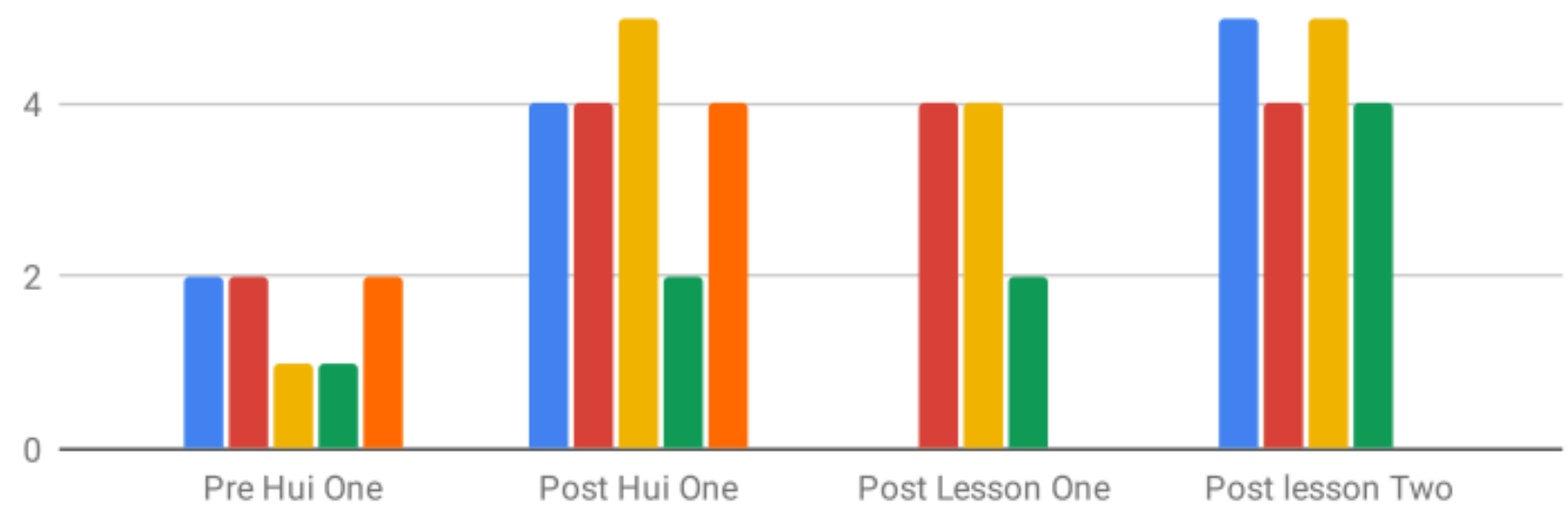

Figure 2. Confidence in Designing Lessons with Computational Thinking Elements as Reported by Participants Over the Duration of the Project 


\section{Participant A Participant B $\square$ Participant C $\square$ Participant D $\square$ Participant E}

6

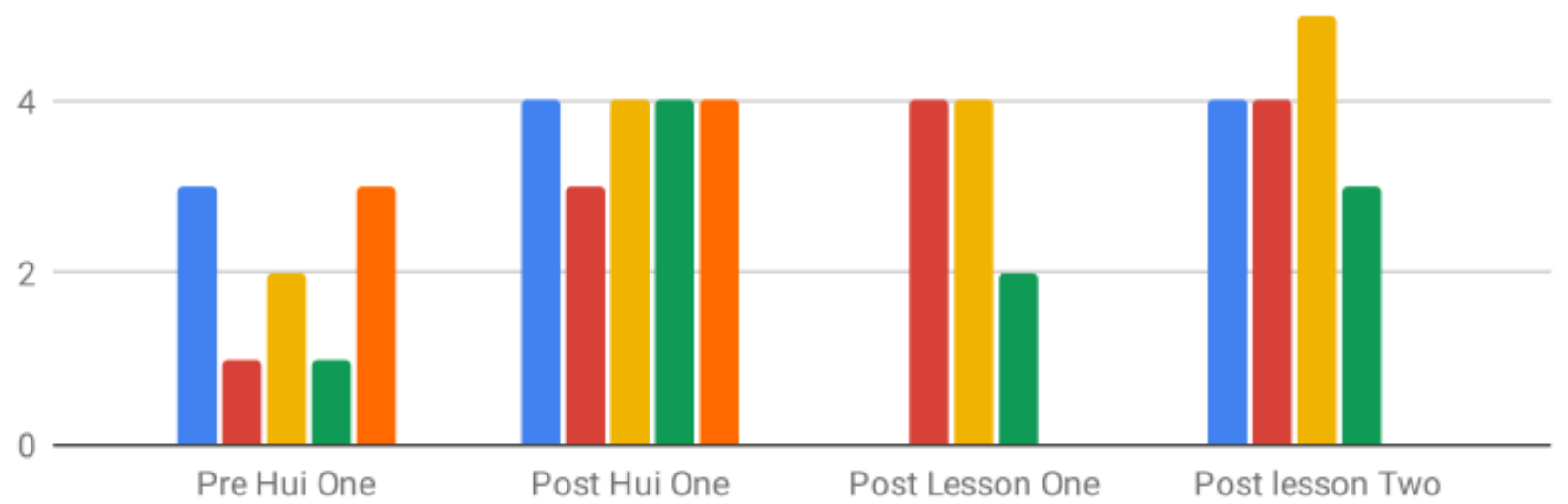

Figure 3. Confidence in Giving Feedback/Feed-forward/Clarification in regards to Computational Thinking Concepts as Reported by Participants Over the Duration of the Project

The exception to this was participant 'A', who only had an increase in confidence in lesson design and ability to give feedback after the first hui, while their awareness and understanding of computational thinking remained the same, as shown in Figure 1. This was due to the participant's prior knowledge of the topic as they identified that they had studied computational thinking in the past. The benefit for them came through utilising the knowledge in the context of their practice, rather than just being aware of it, as suggested by their increase in confidence in the other two areas over the course of the project, as shown in Figures 2and 3. This is consistent with Yadav et al's (2017) findings that recognise contextualisation to be at the heart of knowledge application, rather than a knowledge of the subject matter itself.

The data suggests that in most cases, the initial hui prompted significantly more growth than the creation, delivery, and reflection of lessons over the course of the project, but I found that this was inconsistent with kōrero from participants. When asked about the usefulness of the introductory hui in comparison with the collaborative wānanga, participants stated that they "learned a lot from the practical activities of the first hui" (observation, July 26, 2019), but found the wānanga to be especially valuable, particularly in the areas of sharing ideas and hearing about what other participants were trying in their learning areas. This is important because it meant that participants found benefit and growth in the process of sharing and reflecting on their experiences, which was a key part of the support provided by the project and aligns directly with the Māori concepts of ako and wānanga.

All four participants specifically mentioned that wānanga were a highlight of their experiences, and participants often found that learning activities were both applicable and effective across several learning areas. Participants regularly made suggestions to each other about ways that their activities could be improved and how they could apply similar ideas to their own learning areas. They mentioned sharing resources with other participants, as well as other teachers within the school who weren't participating in the project (observation, July 26, 2019). This demonstration of integrated ako was key to my own vision of success for the project. These findings demonstrate the value of exploration in transformation of practice over the use of expert-led instruction and provided resources, as found by Garet et al. (2001). This also indicates that participants felt 
a degree of confidence and understanding of the activity and content that it explores, and by extension, an understanding of computational thinking.

Participants identified that simplification of concepts, as well as providing ample time to reflect, discuss, and explore the implementation of the concepts in their own classroom was key to growth in their confidence and understanding (observation, July 26, 2019).

Overall, all four participants stated that they felt more confident in their ability to develop and deliver lessons that use computational thinking concepts than they did before the project (Figure 1, Figure 2, Figure 3). Two of the four participants also added that while they do feel somewhat more confident, additional time, experimentation, and exploration (especially in the area of student outcomes) are key to affirming their understanding and application of their learning (observation, July 26, 2019). This means that supporting these teachers helped them to build their agency in developing high-quality lessons that are aligned with digital technologies curriculum.

\section{IMPACT AND NEXT STEPS}

The goal of this project was to understand how supporting teachers in subject areas other than digital technologies helps them to build their agency in developing lessons that are aligned with digital technologies curriculum. This project has allowed teachers and students to apply and explore computational thinking principles with a greater level of confidence. The teachers who participated gained confidence in the areas of understanding, lesson design, and feedback and feedforward in relation to computational thinking. While participants have identified that they are still not entirely comfortable in this area, this confidence will benefit them as they continue to explore aspects of computational thinking in their own learning areas.

Some limitations of the project include a lack of participants, and insufficient follow-up to determine the long-term impact on teacher practice. The project began with five participants, which was reduced to four after the initial hui. This meant that the data was limited to the experiences of the sample group, and findings may not be accurate if replicated with a larger group of participants. The project scope did not allow for any follow-up with participants beyond the initial project. As a result of this, there is no data on the long-term impact of the learning, including whether lessons continued to be delivered after the project's conclusion.

As a result of the project and its findings, the school involved is looking at ways that they can now implement the learning from the pilot programme across other areas of the school. Some of this will involve delivering similar content on a whole staff level, but also looking at ways of encouraging learning areas to identify where they are already using computational thinking in their units. The overall objective is to create a school-wide unit plan that allows learning areas to identify where computational thinking is taught in their units and which progress outcomes they fulfil.

The participating school has begun exploring potential ways of supporting non-participating teachers with the applications of computational thinking concepts to their lessons. The initial project required extensive resources to relieve participating teachers of their classes so that they would be able to attend hui, and unfortunately, this means that the direct continuation of the project with all teachers at the school is not possible. It is possible that the project takes a similar approach to other initiatives in the school, where one teacher from each learning area is appointed the "champion" who engages directly with the content and then disseminates information to other learning area members afterwards. While this is a much more cost-effective route, it means that 
"non-champions" would not be exposed to the same direct learning, and wānanga aspect of the original project - something that participants identified as a significant benefit of the project. By extension, "non-champion" teachers may not see the same understanding and growth as teachers who participated in the initial project. The aim of this project was to improve access to quality digital technologies education in New Zealand, and this course of action may not contribute to this aim as effectively.

Another iteration of this project has been planned to be run in the future. Changes to content and structure have been made based on the feedback of participants from this project. This feedback was received after the results of the research had been disseminated to participants during the final hui. Some of these changes will include the simplification of hui one content, and the inclusion of more interactive activities to support a strong foundation of understanding. Other changes may include monitoring the effects of the lessons on student outcomes, lengthening the project duration, and weaving observation into the process to ensure quality of computational thinking education. These changes would strengthen the research component of the project, provide insight into the effects on student learning, and increase the project's value to the education community.

Towards the end of this project I reached out to Kia Takatū ā-Matihiko, an initiative developed by the New Zealand Ministry of Education to support schools to implement the new digital technologies curriculum. Kia Takatū à-Matihiko were impressed by the impact of the approach used and how the collaborative and reflective nature of the process improved the confidence of participating teachers in developing and delivering lessons that teach computational thinking concepts. They offered to support me in sharing the work we had done through Collaborative Kete with other schools in the country through the creation of a showcase video. This video would be made available to other schools on the Kia Takatū a-Matihiko website. This was an excellent opportunity for our journey through this kaupapa to inform other schools in their own learning and support them to gain more equal access to quality digital technologies education than they otherwise might have had.

\section{REFERENCES}

Allan, V., Barr, V., Brylow, D., \& Hambrusch, S. (2010, March). Computational thinking in high school courses. Proceedings of the 41st ACM technical symposium on Computer science education (pp. 390-391). ACM.

Bishop, R., Berryman, M., Cavanagh, T., \& Teddy, L. (2007). Te Kōtahitanga Phase 3 Whānaungatanga: Establishing a culturally responsive pedagogy of relations in mainstream secondary school classrooms. Wellington: Ministry of Education, 81-90.

Blum, L., \& Cortina, T. J. (2007). CS4HS: an outreach program for high school CS teachers. ACM SIGCSE Bulletin, 39(1), 19. https://doi.org/10.1145/1227504.1227320

Garet, M. S., Porter, A. C., Desimone, L., Birman, B. F., \& Yoon, K. S. (2001). What Makes Professional Development Effective? Results From a National Sample of Teachers. American Educational Research Journal, 38(4), 915-945. https://doi.org/10.3102/00028312038004915

Guskey, T. R., \& Yoon, K. S. (2009). What works in professional development?. Phi delta kappan, 90(7), 495-500.

Hickmott, D., \& Prieto-Rodriguez, E. (2018). To Assess or Not to Assess: Tensions Negotiated in 
Six Years of Teaching Teachers about Computational Thinking. Informatics in Education, 17(2), 229-244. https://doi.org/10.15388/infedu.2018.12

Imberman, S. P., Sturm, D., \& Azhar, M. Q. (2014). Computational thinking: Expanding the toolkit. Journal of Computing Sciences in Colleges, 29(6), 39-46.

Joyce, B., \& Showers, B. (1980). Improving inservice training: The messages of research. Educational Leadership, 37(5), 379-385.

Joyce, B., \& Showers, B. (2002). Student achievement through staff development.

Ministry of Education. (2018a, March 12). Technology. http://nzcurriculum.tki.org.nz/The-NewZealand-Curriculum/Technology/Progress-outcomes

Ministry of Education. (2018b, March 12). Technology. https://nzcurriculum.tki.org.nz/The-NewZealand-Curriculum/Technology/Why-study-technology

Morreale, P., \& Joiner, D. (2011). Changing perceptions of computer science and computational thinking among high school teachers. Journal of Computing Sciences in Colleges, 26(6), 71-77.

Morreale, P., Joiner, D., \& Chang, G. (2010). Connecting undergraduate programs to high school students: teacher workshops on computational thinking and computer science. Journal of Computing Sciences in Colleges, 25(6), 191-197.

Ministry of Education. (2007). The New Zealand Curriculum. Wellington: Learning Media.

Timperley, H., Wilson, A., Barrar, H., \& Fung, I. (2007). Teacher professional learning and development: Best evidence synthesis iteration (BES). Wellington: Ministry of Education.

Timperley, H., Wilson, A., Barrar, H., \& Fung, I. (2008). Teacher professional learning and development.

Yadav, A., Hong, H., \& Stephenson, C. (2016). Computational Thinking for All: Pedagogical Approaches to Embedding 21st Century Problem Solving in K-12 Classrooms. TechTrends, 60(6), 565-568. https://doi.org/10.1145/2576872

Yadav, A., Stephenson, C., \& Hong, H. (2017). Computational thinking for teacher education. Communications of the ACM, 60(4), 55-62. https://doi.org/10.1145/2994591

Yadav, A., Mayfield, C., Zhou, N., Hambrusch, S., \& Korb, J. T. (2014). Computational thinking in elementary and secondary teacher education. ACM Transactions on Computing Education (TOCE), 14(1), 5 .

The opinions expressed are those of the paper author(s) and not He Rourou or The Mind Lab.

He Rourou by The Mind Lab is licensed under a Creative Commons Attribution-NonCommercial-ShareAlike 4.0 International License, except where otherwise noted. [ISSN 2744-7421] 


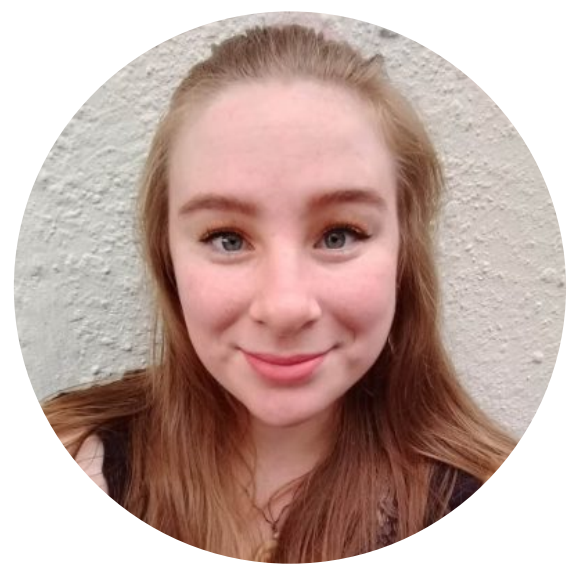

Jessica Petersen

Jessica Petersen (Taranaki Iwi) is a digital technologies teacher in Tāmaki Makaurau. She is an avid researcher who believes in the potential for digital technologies as an outlet for creativity, mechanism for growth, and tool for driving change in our communities.

Jessica holds a Master of Teaching and Education Leadership and a Bachelor of Information and Communication Technologies, specialising in software engineering. Currently, she is pursuing another Masters degree in Contemporary Education giving her a broader understanding of education in Aotearoa New Zealand and its outcomes.

In line with her vision of using education to combat inequality in our school systems, she has a deep interest in te ao Māori and its power to revolutionise the way we learn, live, and interact with the world. 